\title{
Channel Estimation Techniques for MIMO-OFDM Systems over Frequency Selective Fading Channels
}

\author{
Seda Üstün Ercan ${ }^{* 1}$ \\ Accepted $3^{\text {rd }}$ September 2016
}

\begin{abstract}
Wireless channel is very complex because of both frequency and time selectivity. In order to overcome the adverse effects of multipath fading in mobile communication channels, channel estimation must be performed. There are three kinds of channel estimation methods: pilot based, blind and semi-blind. In pilot based channel estimation, some of data symbols are used to estimate channel. In blind channel estimation statistical properties of channel are used. In semi-blind channel estimation information from both data symbols and statistical properties is utilized. In this study, pilot based and semi-blind channel estimation are used to estimate the channels with various frequency selectivity in multiple input multiple output-orthogonal frequency division multiplexing (MIMO-OFDM) systems. Semi-blind channel estimation is done by using independent component analysis (ICA). Simulation results show that if the frequency selectivity of the channel is high, semi-blind channel estimation technique can be used instead of pilot based channel estimation. Thus with a using a small number of pilot bits, more data can be used in the MIMO systems.
\end{abstract}

Keywords: MIMO-OFDM, pilot based, semi-blind, channel estimation, ICA

\section{Introduction}

A large channel capacity exists for wireless systems with multiple transmit and receive antennas [1]. In wireless communication systems, with the use of multiple antennas on the transmitter and receiver antennas, multiple input multiple output (MIMO) systems are obtained. MIMO systems are one of the most popular research areas of wireless communications [2]. Multiple input multiple output-orthogonal frequency division multiplexing (MIMO-OFDM) which has high spectral efficiency is the key technology of today's wireless communication systems and it has become popular technique for transmission of signals over wireless channel [3]. Channel estimation algorithms can be categorized into three groups [4]. In pilot based channel estimation, value of previously known pilot bits are inserted into the transmitted signal is compared to the received value in the receiver and in pilot based channel estimation one dimensional pilot placement (block and comb) and two dimensional pilot placement (rectangular and diamond) are used [5]. In blind channel estimation, algorithms often exploit the second-order stationary statistics with high computational complexity. Therefore blind channel estimation isn't used frequently. In semiblind channel estimation algorithms both small number of pilot bits and statistical properties of channel are used. In literature there are numerous channel estimation algorithms for example ICA [6,7], singular value decomposition (SVD) [8], subspace methods [9] All algorithms have advantages and disadvantages. But in semi-blind channel estimation, more bandwidth efficiency are obtained than pilot based channel estimation because of less pilot usage.

\section{MIMO-OFDM Channel}

2x2 MIMO-OFDM communication system using Alamouti

Department of Electrical and Electronics Engineering, Ondokuz Mayls

University, 55139, Samsun/Turkey

Corresponding Author: Email: sedau@omu.edu.tr

Note: This paper has been presented at the $3^{\text {rd }}$ International Conference on Advanced Technology \& Sciences (ICAT'16) held in Konya (Turkey), September 01-03, 2016.

This journal is @ Advanced Technology \& Science 2013 illustrated in Fig. 1[10].

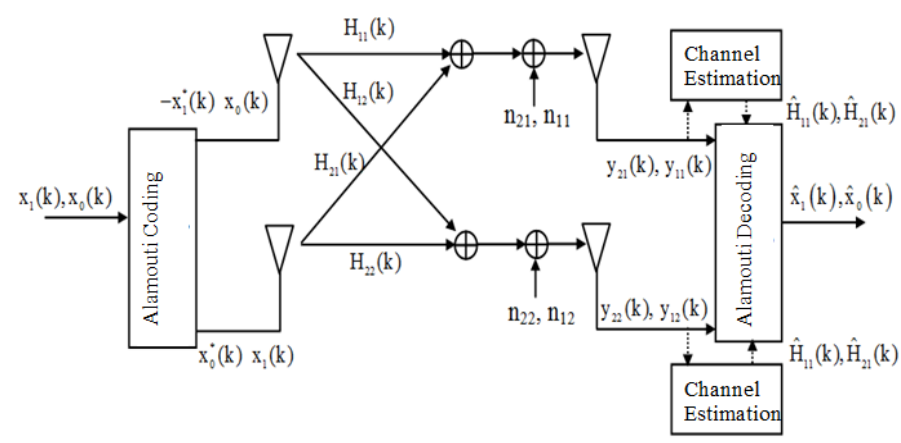

Figure 1. 2x2 Alamouti MIMO-OFDM System

Alamouti's space time block coding for these structures is given formulas (1).

$\mathrm{X}=\left[\begin{array}{cc}\mathrm{x}_{0} & \mathrm{x}_{1} \\ -\mathrm{x}_{1}^{*} & \mathrm{x}_{0}^{*}\end{array}\right]$

A specific $t$ time, $x_{0}$ and $x_{I}$ symbols are respectively transmitted simultaneously from the first and second antennas. The next time $(t+\tau),-x_{1} *$ and $x_{0} *$ are transmitted respectively.

The signals reach the receiving antenna at $t$ and $t+\tau$ time are given in formulas (2-5).

$$
\begin{aligned}
& \mathrm{y}_{11}(\mathrm{k})=\mathrm{x}_{0}(\mathrm{k}) \mathrm{H}_{11}(\mathrm{k})+\mathrm{x}_{1}(\mathrm{k}) \mathrm{H}_{21}(\mathrm{k})+\mathrm{n}_{11}(\mathrm{k}) \\
& \mathrm{y}_{21}(\mathrm{k})=-\mathrm{x}_{1}^{*}(\mathrm{k}) \mathrm{H}_{11}(\mathrm{k})+\mathrm{x}_{0}^{*}(\mathrm{k}) \mathrm{H}_{21}(\mathrm{k})+\mathrm{n}_{21}(\mathrm{k}) \\
& \mathrm{y}_{12}(\mathrm{k})=\mathrm{x}_{0}(\mathrm{k}) \mathrm{H}_{12}(\mathrm{k})+\mathrm{x}_{1}(\mathrm{k}) \mathrm{H}_{22}(\mathrm{k})+\mathrm{n}_{12}(\mathrm{k}) \\
& \mathrm{y}_{22}(\mathrm{k})=-\mathrm{x}_{1}^{*}(\mathrm{k}) \mathrm{H}_{12}(\mathrm{k})+\mathrm{x}_{0}^{*}(\mathrm{k}) \mathrm{H}_{22}(\mathrm{k})+\mathrm{n}_{22}(\mathrm{k})
\end{aligned}
$$

where $\mathrm{H}_{\mathrm{ij}}(\mathrm{k})$ is channel transfer function in the frequency domain for $k$. subcarrier, $i$. transmitter and $\mathrm{j}$. receiver antenna. [ $\mathrm{n}_{1 \mathrm{j}}(\mathrm{k})$, 
$\left.\mathrm{n}_{2 \mathrm{j}}(\mathrm{k})\right]$ is noise power at $t$ and $t+\tau$ moment for $j$. receiver antenna.

For 2x2 Alamouti MIMO-OFDM System, channel estimation coefficients in the receiver are obtained as shown in formulas (69).

$$
\begin{aligned}
& \hat{\mathrm{H}}_{11}(\mathrm{k})=\frac{\mathrm{x}_{0}^{*}(\mathrm{k}) \mathrm{y}_{11}(\mathrm{k})-\mathrm{x}_{1}(\mathrm{k}) \mathrm{y}_{21}(\mathrm{k})}{\left|\mathrm{x}_{0}(\mathrm{k})\right|^{2}+\left|\mathrm{x}_{1}(\mathrm{k})\right|^{2}} \\
& \hat{\mathrm{H}}_{21}(\mathrm{k})=\frac{\mathrm{x}_{1}^{*}(\mathrm{k}) \mathrm{y}_{11}(\mathrm{k})+\mathrm{x}_{0}(\mathrm{k}) \mathrm{y}_{21}(\mathrm{k})}{\left|\mathrm{x}_{0}(\mathrm{k})\right|^{2}+\left|\mathrm{x}_{1}(\mathrm{k})\right|^{2}} \\
& \hat{\mathrm{H}}_{12}(\mathrm{k})=\frac{\mathrm{x}_{0}^{*}(\mathrm{k}) \mathrm{y}_{12}(\mathrm{k})-\mathrm{x}_{1}(\mathrm{k}) \mathrm{y}_{22}(\mathrm{k})}{\left|\mathrm{x}_{0}(\mathrm{k})\right|^{2}+\left|\mathrm{x}_{1}(\mathrm{k})\right|^{2}} \\
& \hat{\mathrm{H}}_{22}(\mathrm{k})=\frac{\mathrm{x}_{1}^{*}(\mathrm{k}) \mathrm{y}_{12}(\mathrm{k})+\mathrm{x}_{0}(\mathrm{k}) \mathrm{y}_{22}(\mathrm{k})}{\left|\mathrm{x}_{0}(\mathrm{k})\right|^{2}+\left|\mathrm{x}_{1}(\mathrm{k})\right|^{2}}
\end{aligned}
$$

\section{Pilot Based Channel Estimation}

In this study rectangular pilot placement (Fig. 2) and diamond pilot placement (Fig.3) are used for the estimation of MIMO channel.

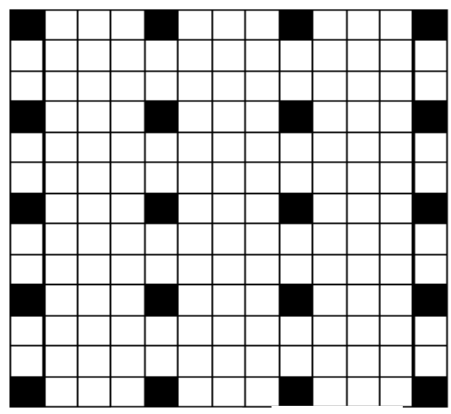

Data Pilot

Figure 2. Rectangular pilot placement

In rectangular structure, pilot bits are placed periodically in the time and frequency domain. In the pilot based channel estimation, the values of the channel at the position of the pilot can be obtained using least squares (LS) and the minimum mean square error (MMSE) [11,12].

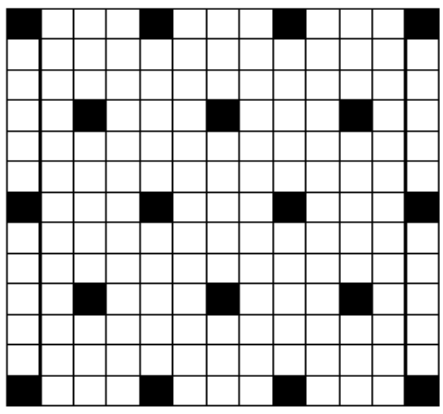

$$
\text { Data Pilot }
$$

Figure 3. Diamond pilot placement

In diamond pilot placement, pilot bits are placed different subcarriers in different times.

\section{Semi-blind Channel Estimation}

In this study a semi-blind algorithm is used for the estimation of frequency selective MIMO channel matrix $H$. In semi-blind channel estimation, firstly pilot bits are located. Then the value of the mixing matrix is determined according to the selected pilot positions. And as it is in the blind channel estimation, channel coefficients are updated using whitening data.

In this study ICA is used as a semi-blind channel estimation. The ICA algorithm is based on a decomposition of the channel matrix $\mathrm{H}$. The aim of ICA is finding the $x$ signals in formulas (10) [13].

$\mathrm{y}=\mathrm{Hx}$

For a good results there are two assumptions in ICA. First; source signals $x$ are independent of each other. The second one is the values in each source signal have non-Gaussian distributions [14].

ICA's preprocessing steps are:

a)Centering: The most basic and necessary pre-processing for ICA is centering. In this step, the observation vector y by subtracting its mean vector $\mathrm{m}=\mathrm{E}\{\mathrm{y}\}$

$\mathrm{y}_{\mathrm{c}}=\mathrm{y}-\mathrm{m}$

b)Whitening: The another useful pre-processing method is whitening. A simple method to perform the whitening transformation is to use the eigenvalue decomposition (EVD) [15] of $y$. That is, decomposition the covariance matrix of $y$ as follows:

$\mathrm{m}=\mathrm{E}\left\{\mathrm{yy}^{\mathrm{T}}\right\}=\mathrm{VDV}^{\mathrm{T}}$

where $V$ is the matrix of eigenvectors of $\mathrm{E}\left\{\mathrm{yy}^{\mathrm{T}}\right\}$ and $D$ is the diagonal matrix of eigenvalues. The observation vector can be whitened by the following transformation:

$$
\begin{aligned}
& \mathrm{y}_{\mathrm{w}}=\mathrm{VD}^{-1 / 2} \mathrm{~V}^{\mathrm{T}} \mathrm{y} \\
& \mathrm{y}_{\mathrm{w}}=\mathrm{VD}^{-1 / 2} \mathrm{~V}^{\mathrm{T}} \mathrm{Hx}=\mathrm{H}^{*} \mathrm{x}
\end{aligned}
$$

where $\mathrm{H}^{*}$ is the mixing matrix. Initial value of $\mathrm{H}^{*}$ is given randomly. Then with a using various algorithms, the last value of $\mathrm{H}^{*}$ has obtained.

ICA method is used in a wide range of applications such as biomedical, finance, engineering. Different algorithms have been developed for these applications. Some of these are Joint Approximate Diagonalization of Eigenmatrices (JADE), Infomax and fixed point algorithm [16].

\section{Results}

In this study, pilot based channel estimation and semi-blind channel estimation are used to estimate the channels with various frequency selectivity. Firstly, two dimensional pilot based channel estimation is performed using rectangular and diamond pilot placement with different pilot ratio $(\mathrm{PR}=4,16,64,256)$ values. Semi-blind channel estimation is done by using ICA with 1,2 and 4 pilot bits. In simulations; ITU pedestrian (Ch1) and vehicular channels (Ch2), 20MHz band width, $200 \mathrm{~Hz}$ Doppler frequency, 2x2 MIMO structure and 1024 subcarriers are used. 


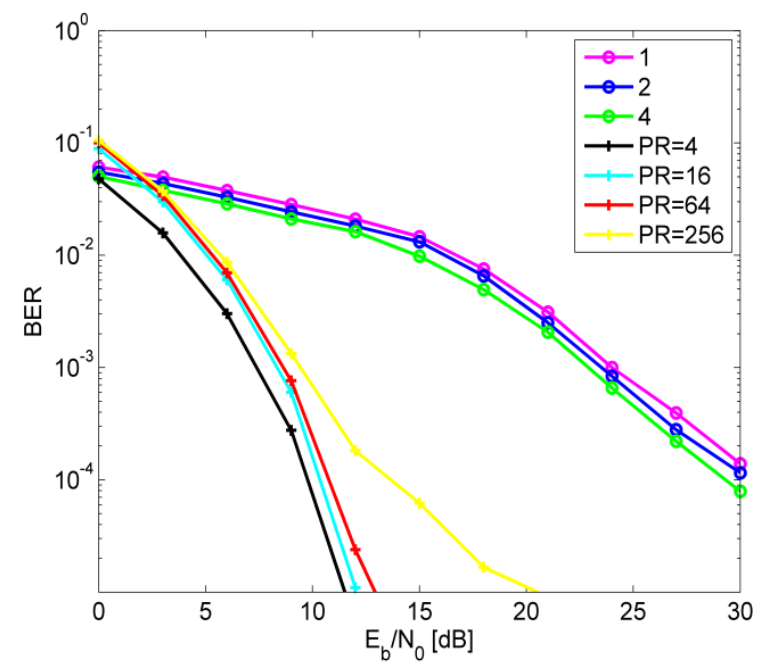

Figure 4. Performance of ICA and diomand pilot placement for Ch1

Diamond pilot placement and ICA based semi-blind channel estimation results for pedestrian channel $\mathrm{Ch} 1$ are given in Fig. 4. In diamond pilot placement and ICA method, different number of pilot bits are used. It is shown that pilot based channel estimation with a diamond pilot placement results are better than ICA results. it is better to use fewer pilot bits, so diamond pilot placement with a $\mathrm{PR}=64$ is suitable to estimate $\mathrm{Ch} 1$.

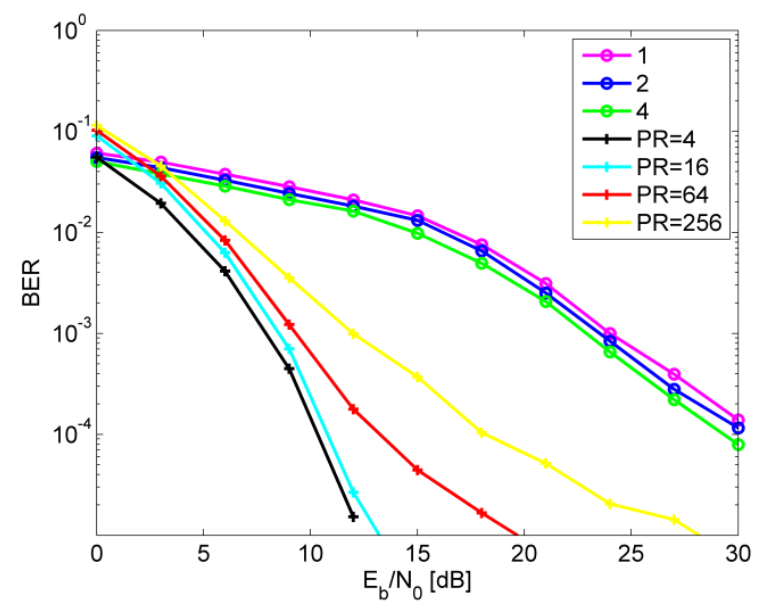

Figure 5. Performance of ICA and rectangular pilot placement for Ch1

In Fig. 5 rectangular pilot placement and ICA based semi-blind channel estimation results are given for $\mathrm{Ch} 1$. It is shown that pilot based channel estimation with a rectangular placement results are better than a semi-blind channel estimation results. $P R=16$ is enough to estimate the $\mathrm{Ch} 2$. So for a pedestrian channel $\mathrm{Ch} 1$ which is less frequency selectivity channel than the vehicular channel $\mathrm{Ch} 2$, pilot based channel estimation results are better than the ICA results. Thus with a using a small number of pilot bits, best performance is obtained.

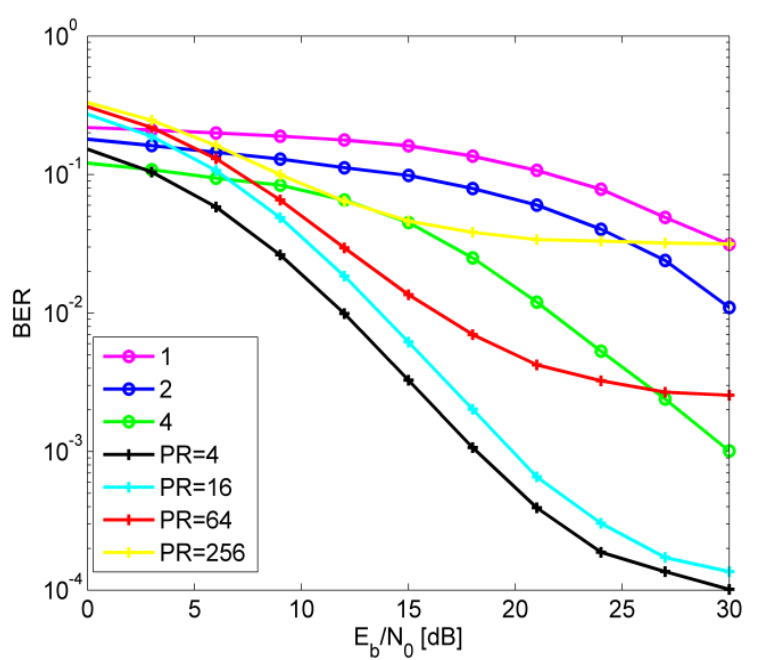

Figure 6. Performance of ICA and diamond pilot placement for $\mathrm{Ch} 2$

In Fig. 6 diamond pilot placement and ICA based semi-blind channel estimation results are given for $\mathrm{Ch} 2$. It is shown that up to $15 \mathrm{~dB}$, diamond pilot placement is better than the ICA. But after $15 \mathrm{~dB}$, ICA (with 4 pilot bits), is better than diamond pilot placement $(P R=256)$. And after $25 \mathrm{~dB}$, ICA (with 2 pilot bits) is better than diamond pilot placement $(P R=256)$ and after $27 \mathrm{~dB}$ ICA (with 4 pilot bits) is better than diamond pilot placement ( $\mathrm{PR}=64)$.

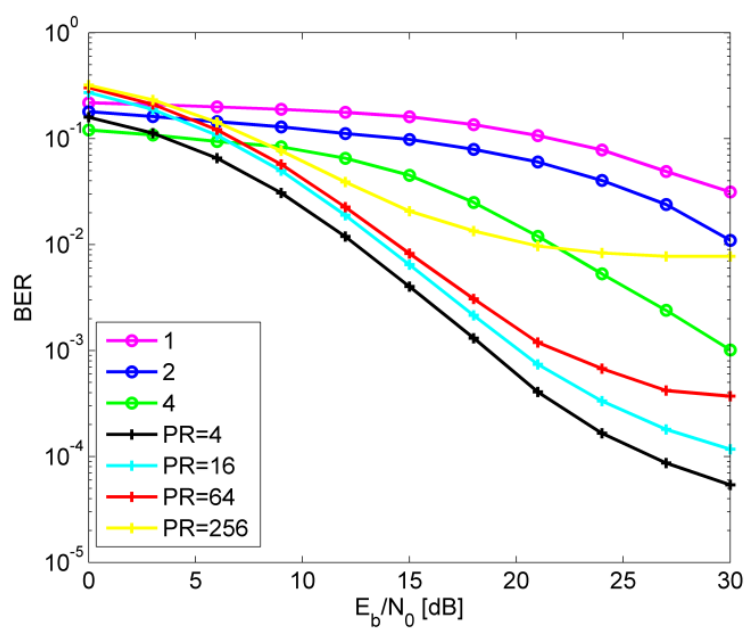

Figure 7. Performance of ICA and rectangular pilot placement for $\mathrm{Ch} 2$

Rectangular pilot placement and ICA based semi-blind channel estimation results for $\mathrm{Ch} 2$ are given in Fig. 7. It is shown that, up to $22 \mathrm{~dB}$, rectangular pilot placement is better than the ICA. But after $22 \mathrm{~dB}$, ICA (with 4 pilot bits) is better than rectangular pilot placement $\mathrm{PR}=4$.

\section{Conclusions}

The results show that if the frequency selectivity of the channel is high and $\mathrm{SNR}>15 \mathrm{~dB}$ for diamond pilot placement and $S N R>22$ for rectangular pilot placement, semi-blind channel estimation technique can be used instead of pilot based channel estimation technique which allows less pilot usage and consequently enhanced more bandwidth efficiency. So it is understood that pilot based channel estimation results aren't always better than the semi-blind channel estimation results. 


\section{References}

[1] Foschini G. J., Gans M. J. On Limits of Wireless Communications in Fading Environment When Using Multiple Antennas, Wireless Pers. Commun, 6, 1998, pp. 311-335.

[2] Telatar E. Capacity of Multi Antenna Gaussian Channels, AT\&T Bell Labs S, 1995.

[3] Foschini G. J. Layered Space-Time Architecture for Wireless Communication in a Fading Environment When Using Multi-element Antennas, Bell Labs Technical Journal, Vol.1, Number. 2, 1996, pp. 41-59.

[4] Wan F., Zhu W.-P., Swamy M. N. S. A Semiblind Channel Estimation Approach for MIMO-OFDM Systems, IEEE Transactions On Signal Processing, Vol.56 Number.7, 2008, pp. 2821-2834.

[5] Engiz B. K., Kurnaz Ç., Sezgin H. Approach for Determining the Optimum Pilot Placement in Orthogonal Frequency Division Multiplexing Systems, IET Communications, Vol.9 Number.15, 2015, pp. 1915-1923.

[6] Xu C., Li H., Chang S. Semi-blind MIMO-OFDM Channel Estimation Based on ICA and Pilot Carriers, 2011 IEEE International Conference on Signal Processing, 14-16 Sept. 2011.

[7] Haiyuan, L., Jiancheng, S., Blind MIMO-OFDM Channel Estimation Based on ICA and KRLS Algorithm, 5th International Conference on Wireless Communications, Networking and Mobile Computing, pp. 1-5, 2009.

[8] Edfors O., Sandell M., van de Beek J. -J., Wilson S.
K., Ola Borjesson P. OFDM Channel Estimation by Singular Value Decomposition, 1996, pp.923-927.

[9] Zaier, A., Bouallegue R., Blind Channel Estimation Enhancement for Mimo-OFDM Systems under High Mobility Conditions, International Journal of Wireless \& Mobile Networks (IJWMN), Vol. 4, Number. 1, 2012.

[10] Ercan S. Ü., Kurnaz Ç. Investigation of Blind and Pilot Based Channel Estimation Performances in MIMO-OFDM Systems, IEEE 23th Signal Processing and Communications Applications Conference, 16-19 May 2015, Malatya, Turkey.

[11] Patil S. M., Jadhav A. N. Channel Estimaiton Using LS and MMSE Estimators. International Journal on Recent and Innovation Trends in Computing and Communication Vol.2, Issue. 3, 2014, pp. 566-570.

[12] Kewen L., XinKe. Research of MMSE and LS channel estimation in OFDM systems, The $2^{\text {nd }}$ International Conference on Information Science and Engineering, 2010, pp. 2308-2311.

[13] Hyvärinen A., Oja, E.. Independent Component Analysis: Algorithms and Application, Neural Networks, 13 (4-5): 2000, pp. 411-430.

[14] Hyvarinen A., Karhunen J., and Oja E. Independent Component Analysis, Wiley-Interscience, 2001.

[15] Meyer C. D. Matrix Analysis and Applied Linear Algebra. 2000, Cambridge, UK.

[16] Naik, G.R., Kumar, D.K., An Overwiew of Independent Component Analysis and its Application. Informatica, 35, 2011, pp. 63-81. 